\title{
Fronteras y representaciones fronterizas: aproximaciones comparativas entre Estados Unidos y América Latina
}

\author{
Marcos Cueva Perus*
}

\begin{abstract}
Resumen. El artículo se propone realizar una aproximación comparativa entre las nociones de frontera y las representaciones fronterizas entre Estados Unidos y América Latina y el Caribe. Constata que el número de conflictos fronterizos en el mundo ha venido disminuyendo, que Estados Unidos concibe la frontera con un mito nacionalista que encarna la fe cuasi religiosa en el libre mercado y la democracia, y que el subcontinente americano, con fronteras más complejas que las estadounidenses, ha mostrado en este terreno una extraordinaria estabilidad desde hace décadas. El artículo alerta sobre los riesgos que pueden entrañar, al trasladarse a otros países, las representaciones fronterizas estadounidenses, que incluyen por otra parte la problemática de la segmentación multicultural. A mérica Latina y el Caribe tienen fronteras estables, pero son vulnerables a las representaciones fronterizas provenientes del exterior.

Palabras clave: frontera, Estados Unidos, América Latina, mitos, representaciones.
\end{abstract}

\begin{abstract}
A bstract. This article uses a comparative approach regarding frontier symbols and myths among the United States, Latin America and the Caribbean. Although wars fought over frontiers have greatly diminished throughout the world, the conception of frontier still held by the United States is that of a nationalist myth which embodies a semi-religious faith in the free market and democracy. On the other hand, Latin A merican and Caribbean countries, whose frontiers are far more complex, have shown extraordinary stability for several decades. This paper points out the risks involved in the spread of United States' notions of frontier which, in addition, go hand-in-hand with the problem of multicultural segmentation. Although Latin American and Caribbean frontiers may be stable, they are vulnerable to the infiltration of foreing frontier representations.

Keywords: frontier, United States, Latin America, myths, representations.
\end{abstract}

* Instituto de Investigaciones Sociales de la Universidad Nacional Autónoma de México (IIS-UNAM). Correo electrónico: cuevaperus@yahoo.com.mx 


\section{Introducción}

El objetivo de este texto es establecer, sobre la base de un breveestudio comparativo, las principales concepciones de la frontera en distintas latitudes del mundo, pero sobre todo las diferencias de "representaciones fronterizas" más importantes entre Estados Unidos y los países del subcontinente americano. Es posible suponer que el debilitamiento del Estado nacional por la globalización seha acompañado del debilitamiento de las "fronteras" por desterritorialización. Pero en realidad no es seguro que así sea: por el contrario, una experiencia como la méxico-norteamericana -por citar sólo una- sugierea la vez el reforzamiento dela frontera física y la tentativa dedisolución de las fronteras abstractas (lo que no excluye nuevas formas de intervencionismo). En el curso de este estudio, además de explicar lo que entendemos por "representaciones fronterizas", habremos deexplorar el significado de esta aseveración: puede ser que las fronteras físicas se desval oricen en términos relativos, pero no ocurrelo mismo con los mitos que las acompañan. Bien vale la pena agregar que la reflexión sobre el tema ha sido escasa.

Desde hace al gunos años, el número de conflictos armados fronterizos en el mundo ha disminuido sensiblemente, aunque unas pocas fronteras -cada vez menos- sean todavía fuente de inestabilidad. La historia del siglo xx estuvo llena de conflictos fronterizos que tenían que ver en su gran mayoría con los procesos de descolonización: en muchos territorios, las fronteras nacionales oficiales eran difíciles de establecer y conservar, ya que se yuxtaponían con las fronteras de grupos étnicos, clánicos, tribales u otros, como sucediera con frecuencia en el continenteafricano. La frontera nacional solía no coincidir con las fronteras de esas comunidades, ni con sus representaciones del espacio. Por otra parte, al gunos militarismos, como el alemán y el japonés, buscaron en los años treinta del siglo xx desdibujar de manera brutal las fronteras nacionales establecidas (Europa Central y del Este, Pacífico asiático), pero al grado de buscar el exterminio de los habitantes que vivían dentro de ellas. Antela impotencia de la Sociedad de Naciones, las fronteras nacionales debían desaparecer para dejar lugar alas fronteras "históricas" de los "espacios vitales" (el Lebensraum de los ale- 
manes). En cierto modo, estas políticas belicistas habían comprendido a su manera la práctica de las potencias col oniales, para las cuales el espacio fronterizo no terminaba en el espacio nacional dela metrópoli. Todos los espacios centrales requerían de sus respectivas periferias para asegurarse mercados en la competencia internacional. La frontera llegaba tan lejos como lo permitieran los mercados, la competencia y los rivales.

En el mismo siglo xx, la historia de las fronteras en A mérica Latina y el Caribe fue relativamente pacífica salvo en puntos muy localizados, y la mayoría delas disputas fueron final mente resuel tas, aunque no faltaron -como en el siglo xIx- intervenciones extranjeras, en su mayoría estadounidenses. Pese a esta estabilidad relativa, los espacios fronterizos latinoamericanos y caribeños, mal conocidos y peor integrados desde tiempos coloniales, siguen siendo hasta hoy territorios singulares, "espacios-refugio" donde proliferan fenómenos como el narcotráfico, el contrabando y migraciones diversas. Estos espacios siguen planteando problemas de regionalismo, y no está de más recordar quelos Estad os nacionales del subcontinenteamericano seformaron más por desintegración que por la integración del mercado interno. Con todo, los espaciosfronterizos latinoamericanos y caribeños ya no plantean el problema del separatismo abierto, como llegara a ocurrir en el pasado (con Panamá en 1903, por ejemplo).

A diferencia de los países centrales, en los periféricos la representación del espacio fronterizo - más al lá dela frontera física inmediataes mucho más limitada y local, por más que pueda tener un carácter más comunitario. Dicho en otros términos, para un al emán la frontera desu nación puedellegar hasta dondellega una transnacional alemana con la cual se identifica, o hasta dondellega una fundación al emana para la cual trabaja, o incluso hasta donde se instala un soldado alemán en una misión de paz (como en los Balcanes): no por estar en otro país deja de sentirse alemán, y la "representación fronteriza" se establece entonces en otro lugar, quesiempre va "un poco más lejos". La frontera dela nación no se reduce a la frontera nacional física, sino que constituye una frontera "abstracta", lo que habremos de llamar una "representación fronteriza", por lo demás bastante amplia. Desde estemismo punto devista, el abanico de "representaciones fronte- 
rizas" de un habitante de un país central puede ser tan amplio y variado como lo permitan la actividad transnacional y la diversidad de intereses en el exterior. En los países periféricos, en cambio, es frecuente que la "representación fronteriza" se agote en el espacio local: un indígena o un campesino mexicanos difícilmente pueden representarse un espacio fronterizo ampliado (salvo que entren en contacto con la transnacional o que migren al exterior), que a veces no abarca ni siquiera la totalidad del Estado nacional, o no va más allá de la región o del pueblo. Hemos de volver sobre esta problemática: la frontera nacional no se agota en la frontera física y oficialmente delimitada. De paso, puede afirmarse que la "representación" del Otro en el ser periférico suele ser más limitada que la del habitante del país central, por las diferencias entre centros y periferias en el alcance de las actividades económicas.

No está de más detenerse en lo que las "representaciones" -y en particular, las "representaciones fronterizas"- pueden significar. De entrada, es posible que las "representaciones" sean identificadas con ideologías: cuando Estados Unidos, por ejemplo, considera a finales del siglo xIX que la "Conquista de la frontera" ha de seguir con la expansión en el exterior, se trata desdeluego deuna expresión ideológica que responde a determinados intereses dominantes, y que, por cierto, no implica forzosamentela ampliación dela frontera física, aunquesí de la abstracta (con la injerencia económica y política, por ejemplo, aunque sea el momento dela guerra deanexión en Cuba, Puerto Rico y las Filipinas). Aunqueideológica, es una representación colectiva en la medida en que hunde sus raíces en un "arquetipo" o un "inconsciente" común en la potencia del Norte: en otros términos, la ideología del Destino Manifiesto recurre a los mitos de la frontera (de los pioneros, los colonos y los vaqueros) para legitimarse. Es una representación en la cual, por diferencia con otros Estados nacionales, no cabela idea definitud: la frontera es "ilimitada" para los "elegidos de Dios", y adquiere así un carácter casi religioso. Se trata así de una ideología, pero no cabe el reduccionismo: ésta hunde sus raíces en "representaciones fronterizas" compartidas por amplios segmentos de la población, aunque algunos se hayan opuesto a continuar la expansión en el exterior. 
Al mismo tiempo, podemos sostener que estas representaciones, que desbordan la frontera física, tienen que ver con un imaginario que puede ser el de la nación entera. Como lo ha señalado Peter Burke (Burke, 2000: 208), la diferencia entrela historia delasmentalidadesy la de las representaciones no es demasiado grande, de tal forma que las "representaciones fronterizas" pueden formar partedelas mentalidades de algún colectivo, intereses dominantes incluidos. No se trata, desde luego, de un imaginario que tenga que ver con la "imaginación" y queestédivorciado dela realidad, sino con "imágenes mentales" de lo real y creencias sobre el mismo, distorsionadas o no, pero que de todos modos hacen que la subjetividad influya sobre "condiciones de vida material" concretas. Desde este punto de vista, las re presentaciones distan mucho de ser meras ideologías. Como lo explica Juan Camilo Escobar -en medio de un largo debateen Francia que involucrara a varias disciplinas-, es a la sociología a la que tocó acoger la noción de imaginario en la de representación de las "condiciones materiales de vida" (Escobar Villegas, 2000: 65). El autor de referencia considera que "Ios imaginarios pueden definirse como los conjuntos de ideas-imágenes que sirven de relevo y de apoyo a las otras formas ideológicas de las sociedades, tales como los mitos políticosfundadores delas instituciones depoder" (Escobar Villegas, 2000: 67). Así pues, por lo menos en el caso estadounidense, el imaginario de la frontera ha terminado por convertirse en un mito fundador, al mismo nivel que la llegada de los primeros peregrinos y los "Padres Fundadores" de la costa Este, y en esa medida, en un mito que utilizan las instituciones de poder. Cada sociedad tiene su imaginario colectivo (o sus "imaginarios" en plural), y éste no está por lo demás desvinculado de otra noción, la de mentalidades, como ya hemos visto. En la mentalidad estadounidense, la expansión ilimitada de la frontera es un mito fundador alimentado desde el poder, pero compartido por un pragmatismo generalizado: es una peculiar "representación fronteriza", que va desde luego mucho más allá del espacio físico. Así pues, si la frontera física es tangible, la representación de la "frontera abstracta" remite a la vez a una ideología, un mito (que puede ser fundador, como en el caso de Estados Unidos), un imaginario y una evolución histórica precisa 
de las mentalidades. Cierto comportamiento del estadounidense fuera de su país puede revelar de inmediato este imaginario, en tanto cualquier espacio es considerado de modo impermeable como suyo y objeto de apropiación. En todo caso, no todas las naciones tienen las mismas "representaciones fronterizas", ni por tanto el mismo imaginario sobre su lugar en el mundo.

El problema dela frontera se plantea de modo distinto en distintas latitudes. Es interesantesubrayar cómo, en el caso deEstados Unidos, la frontera se asocia, entre otras cosas, con "pulsiones bélicas" que desembocan desdefinales del siglo xix en la ideología del Destino Manifiesto: es un caso único en el mundo. En los últimos tiempos, por el fenómeno de la globalización, el sentido dela soberanía se ha debilitado en muchos Estados nacional es: ello ha provocado quese borren las fronteras entre los asuntos internos y los asuntos exteriores de Estados Unidos, por lo menos desde la visión estadounidense. Frontera y soberanía nacional están disociadas en la "representación del espaciolímite" estadounidense por razones que habremos de abordar más adelante.

En Europa, el problema delas fronteras se plantea de otro modo: la integración dentro de la Unión Europea (UE) debería conducir a la desval orización relativa del Estado nacional. Por su parte, la Federación Rusa sigue teniendo fronteras relativamente inestables desde el punto de vista político-ideológico, y en A sia los conflictos fronterizos se han reducido sensiblemente en los últimos años. De hecho, sólo queda un caso en el cual las fronteras físicas en el espacio distan mucho de estar claramente establecidas: en el conflicto palestino-israelí. La disminución de los conflictos fronterizos se ha acompañado del retroceso de las "pulsiones bélicas", salvo para Estados Unidos. Desdeestepunto devista, el mundo dehoy es mucho más paćficico queel deayer, si seconsidera el origen añejo de la formación de los Estados nacionales y sus respectivos territorios. ¿A caso se ha llegado a una pacificación definitiva eirreversible de los conflictos armados fronterizos y de las fronteras físicas? No es una posibilidad que deba descartarse, pero ello no anula la existencia de las fronteras abstractas y otro tipo de conflictos por las "representaciones fronterizas". 


\section{Potencias y conflictos fronterizos}

Un buen punto de partida consiste en observar, desde el punto de vista de las relaciones internacionales, el sentido de la frontera para distintas potencias en el mundo. Desdeel momento en quese inventó el arma atómica, ello parece haber supuesto la relativa desvalorización delas fronteras territoriales y del al cance de los conflictos fronterizos. Incluso entre países que no son grandes potencias, como India y Pakistán, un conflicto de envergadura por un territorio como el de Cachemira se ha vuelto impensable, dado que ambos países se han amenazado con la escalada nuclear. Desde 1945, por lo menos entre las grandes potencias, el mundo entró en la estabilización y la relativa desvalorización de las fronteras nacionales como fuente de conflicto bélico. Si bien siguen existiendo puntos de tensión (como en la península coreana o en el estrecho deTaiwán), el relativo equilibrio defuerzas nucleares hace impensables conflictos de gran envergadura. Desde este punto de vista, la globalización no ha llevado al debilitamiento de los Estados nacionales, en particular de los más fuertes: simplemente se ha instalado una "geometría variable" de los equilibrios de fuerza, cuyos orígenes se remontan a 1945. Si en esa época Estados Unidos tenía el monopolio del arma nuclear (cosa de la que aprovechó para atacar a Japón), ahora la situación es distinta y mucho más diversificada. Cualquier escalada armamentista parece ahuyentar en realidad las posibilidades de un conflicto armado real. En los países periféricos, por otra parte, el final de los procesos de descolonización parece haber asegurado la estabilidad de las fronteras físicas.

La progresiva estabilización delas fronteras, quellega hasta la paz actual, no es ajena a la desaparición de los imperios formales: para principios del siglo xxI, ya no queda ninguno deellos (Estados Unidos puede considerarse un imperio informal). "De manera contraria a la aventura estado-nacional, el proyecto imperial parte de una fórmula que niega la idea misma de frontera", considera Bertrand Badie, ya que "la frontera es ilegítima frente a la verdad revelada" (Badie, 1995: 22), ${ }^{1}$

\footnotetext{
${ }^{1}$ Para las referencias en francés (véase bibliografía al final), la traducción es nuestra.
} 
que es la del emperador. Como veremos más adelante, existen razones para pensar, a partir de la afirmación anterior, que efectivamente Estados Unidos sigue siendo un imperio informal, pero imperio al fin y al cabo. En todo caso, Badie se remonta hasta la paz de Westfalia, a mediados del siglo XVII, para mostrar los orígenes de un orden territorial riguroso, que echa sus primeras raíces en Europa y consagra la concepción política del espacio (Badie, 1995: 253), aun por encima de las diferencias étnicas, religiosas u otras. Para el autor, los territorios estarían perdiendo significado en la mundialización ante la primacía de redes dela más diversa índole: circuitos financieros, intercambios comerciales, difusiones de ondas e imágenes, migraciones de personas, solidaridades religiosas, culturales o lingüísticas, y no cabe duda de que Estados Unidos es el primero en aprovecharlas (Badie, 1995: 7). Estados Unidos reconocería en buena medida el orden territorial, pero echaría mano de otros instrumentos - los enumerados- para afianzar sus intereses. Badie recuerda cómo, en el caso de Etiopía, Estados Unidos contribuyó a instalar al final de la Guerra Fría un orden territorial basado en las fronteras étnicas internas (Badie, 1995: 129-130). No está de más recordar cómo, en el conflicto más reciente en la antigua Yugoslavia (años noventa del siglo xx), Estados Unidos respetó las fronteras étnicas establecidas por el titoísmo (en Bosnia Herzegovina y Kosovo) para legitimar la instauración de otra "democracia con base étnica". Algo similar parecía estar sucediendo con el voto delos chítas y los kurdos y la abstención de los sunitas en las elecciones iraquíes de principios de 2005: la instalación de una democracia más del tipo mencionado. En otras palabras, allí donde interviene activamente, Estados Unidos prefiere al mismo tiempo la "democratización" (sobre todo mediante la realización de elecciones) y el establecimiento de fronteras étnicas internas. No es la primera potencia en utilizar este modo de gobierno ("divide y vencerás"), pero, como veremos más adelante, esta política responde a especificidades internas de la sociedad estadounidense.

En otras latitudes, los conflictos étnicos se han atenuado de manera muy llamativa sin que las etnias (con frecuencia de difícil definición) hayan dejado de existir. No está de más señalar que, en todo el siglo $x x$ y hasta principios del xxI, los conflictos étnicos prácticamente 
no han tenido relevancia en los territorios de América Latina y el Caribe, aunque aquí los indios no hayan sido exterminados del modo en que lo fueron en Estados Unidos. Curiosamente, sin embargo, la actual secretaria de Estado estadounidense, Condoleeza Rice, afirmó al momento de asumir el cargo, a principios de 2005, que su país vería por las comunidades indígenas del subcontinente americano (¡). Si el propósito parece injerencista, en realidad traduce un modo "muy estadounidense" de "entender" la realidad del Otro (en este caso, de otros países) como simple espejo de Estados Unidos. En la actualidad, Estados Unidos, como país central, está perdiendo cada vez más la capacidad para representarse la alteridad.

La estabilización de los principios de Westfal ia supone que ya no hay intervenciones legítimas en el territorio del otro, como lo afirmara Pudendorf al final dela Guerra de los Treinta Años (Badie, 1995: 43). Este principio ha sido consagrado por la Organización de Naciones Unidas, aunque algunos países -bajo fuerte influencia de organizaciones no gubernamentales- han buscado relativizarlo en nombre del "derecho de injerencia humanitaria". Con todo, tiene sin duda razón Badie cuando afirma:

e fin de los territorios no consagra la abolición de los espacios: por el contrario, con la mundialización, éstos no dejan de ser reevaluados en su diversidad y flexibilidad. Tampoco marca la desaparición de las fronteras: éstas son incluso más numerosas que antes. No hace desaparecer los terruños ni la sacralización de la tierra y su historia, ahora que la búsqueda identitaria recobra todo su vigor. La ruptura está en otra parte y se inscribe en el ámbito del sentido. Sanciona el declive deun orden sobreel que descansaban la mayoría de los grandes equilibrios internacionales. Este orden se inscribe en una historia que se construyó al ritmo de la invención territorial: dela superación del feudal ismo hasta el Tratado deVersalles, pasando por [...] Westfalia, la concepción política del territorio no dejó de precisarse y de convertirse en uno de los elementos que codifican la escena mundial [...] En este sentido, dotó a la vida internacional de sus principios fundadores, al concebir ésta como una reunión de unidades territoriales soberanas (Badie, 1995: 253). 
¿En verdad se rompió esta codificación de las relaciones internacionales como conjunto de unidades territoriales soberanas? ¿O acaso las fronteras abstractas y la mundialización estarían Ilamadas a relativizar cada vez más las unidades territoriales soberanas? H asta cierto punto, el hecho de que haya más unidades fronterizas que nunca pareciera negarlo. ¿Dedonde procedería entonces la desvalorización de las fronteras en nombre de las búsquedas identitarias? Desde nuestro punto devista, y como habremos de mostrarlo un poco más adelante, este fenómeno traduce en cierta medida, más que la mundialización, una americanización precipitada de cierta parte del mundo. En este mismo sentido, no es casual que no haya tenido demasiado éxito en una A mérica Latina y un Caribe recelosos de esta americanización, así sea por la experiencia de la vecindad con la potencia del Norte y sus ambiciones.

En los años noventa, fue sobre todo en el Este europeo (extinta Yugoslavia) y en las fronteras dela Federación Rusa (Cáucaso, A sia Central, Moldavia) donde el problema de los litigios fronterizos reapareció con cierta fuerza, incluso mayor -en el tiempo- que en ciertos conflictos africanos (Africa de los Grandes Lagos, Africa Occidental). El espacio del Este europeo, "cerrado" por décadas a las influencias occidentales, probablemente haya sido objeto de una rápida americanización, que culminó en la incorporación de numerosos países de la región a la Organización del Tratado del Atlántico Norte. La actitud dela ve, en cambio, resultó más prudente para no atizar el fuego en sus propias fronteras. Los Ilamados PECO (Países de Europa Central y Oriental) fueron catapultados en un tiempo muy breve a la mundialización, sin haber resuelto hasta los años noventa viejos litigios fronterizos: no es de descartar que las redes de solidaridad con los inmigrantes de origen centroeuropeo en Estados Unidos hayan desempeñado un papel importante en la precipitada americanización, aunque estuviera a fin de cuentas contrarrestada por el deseo simultáneo de europeización. Para principios del siglo xxl, de todos modos, los litigios fronterizos en esta última región candente del mundo parecían haber perdido la intensidad de la década previa. De este modo, pueden leerse como conflictos de transición. 


\section{Las singularidades estadounidenses}

Por el modo en que se formó, la potencia estadounidense no sufrió nunca lo que Francois Perroux ha Ilamado "sicosis colectivas de la localización", queestán todas relacionadas con las dimensiones delas fronteras físicas nacionales. Con dos fronteras terrestres estables y sin riesgo alguno de agresión (México y Canadá), dos fachadas marítimas amplias (el Atlántico y el Pać́fico), una frontera alejada con Rusia (Alaska) y una frontera marítima con una pequeña isla (Cuba, a unas cuantas millas deFlorida), la nación estadounidenseno se sintió nunca amenazada, a diferencia de otros países, y en particular deotras potencias. Alemania, por ejemplo, llegó a desarrollar el "complejo de cerco" (Einkreisung) entre 1919y 1939, que sebasaba en hechos reales, y que se acompañó del temor determinista a las privaciones y la derrota, junto con reacciones compensatorias de rechazo y revuelta: ante esta situación, quedaba por sentado queel espacio nacional es el único espacio de seguridad política, los alemanes desplegaron un espíritu revanchista, de defensa de la originalidad de la raza y la cultura, la voluntad de potencia y el deseo de confort material y de la conquista de riquezas (Perroux, 1954: 332). Nada de esto ocurrió en Estados Unidos, dondela frontera se asoció de modo temprano con la libertad y la disponibilidad del espacio, aunque los colonos hayan tardado siglos en cruzar los A palaches y lanzarsea la Conquista definitiva del Oeste. Una vez consagrada esta Conquista, la libertad no reconocía más límites que los que impone la propiedad privada, sagrada en el código del espacio estadounidense desde su fundación.

Estados Unidos tampoco conoció el complejo del “pueblo sin espacio", que llegó a ser activo en A lemania, Japón y en menor medida Italia durante los años treinta del siglo xx. En esta perspectiva, se concibequeel pueblo viveen "fronteras estrechas", o queincluso se "asfixia" en su espacio. Sobre esta base se forman paralelos entre la nación "sobrepoblada" y la nación supuestamente "vacía"; paralelos románticos entre "naciones ricas" (pueblos de rentistas, rentnervöl ker) y naciones "proletarizadas"; y paral el os entre la "amenaza de desbordamiento" y los cataclismos naturales (Perroux, 1954: 334). Aunqueaparentementelejanas en el tiempo, estas interpretacio- 
nes aún se utilizaban para retratar conflictos como el de Ruanda en los años noventa del siglo pasado: debía darse por supuesto -en una perspectiva neomalthusiana- que un "pequeño espacio" albergaba un "exceso depoblación". En realidad, A lemania utilizó en el pasado este "complejo" para omitir que la relación entre las necesidades de una población y los recursos económicos delos quedispone dependemás del tipo y la eficacia dela organización económica que de la densidad poblacional en un territorio dado. Alemania no quería renunciar a la soberanía absoluta que exigía la dominación de un "pueblo guía" (Führervolk) (Perroux, 1954: 333-334). Es probablequeel determinismo geográfico sí exista en Estados Unidos, como ya se ha sugerido en párrafos anteriores. Pero tiene poco que ver con la "sobrepoblación", por lo menos hasta el infundado temor a la "invasión hispana" -la "reconquista"- que reactivó Samuel P. Huntington, y que estaría difuminando la frontera entre México y Estados Unidos (Huntington, 2004: 259). Ciertamente, a diferencia de lo que ocurría en las naciones europeas, los inmigrantes que llegaban a Estados Unidos se toparon con un espacio semivacío, con toda la libertad de ocuparlo: "semi", desdeluego, porqueel "vaciamiento" del territorio supuso el progresivo exterminio dela población indígena nativa. Estados Unidos está lejos de haber sufrido el complejo territorial del "pueblo sin espacio"; por el contrario, la potencia pudo desplegar la idea de la libertad casi infinita para ir ocupando un espacio "casi" vacío: en este proceso no hay reconocimiento del Otro, puesto queno lo hubo para el indígena aniquilado y reducido a reservaciones. El estadounidense tiene una representación del espacio amplia y extendida, pero en la queel Otro es reducido a "espacios reservados" (reservaciones, guetos). Elise Marienstras ha hecho notar cómo la concepción original de la nación estadounidenseno pudo reconocer nunca carta de ciudadanía al guna para los indios y los negros (Marientras, 1976: 209-275). A unque con aspiraciones universal istas, Estados Unidos se encontró muy pronto, luego de la Independencia (1776), en la posición de considerar que la "nación orgánica" tenía dimensiones étnicas insoslayables y favorables a la población blanca (Marienstras, 1976:274).

Es obvio que Estados Unidos, por sus dimensiones, no sufrió del "complejo de la dimensión de la nación", frecuente, en cambio, en 
A mérica Latina y el Caribey en otras latitudes. En particular, Estados Unidos no sufrió el complejo dela "pequeña nación": Perroux observa que tampoco lo han sufrido pequeñas naciones, como Suiza o Bélgica, orientadas al comercio mundial, impregnadas de liberalismo práctico, acostumbradas a tolerar la heterogeneidad lingüística, religiosa y cultural, y habituadas a distinguir entreel espacio económico y el espacio nacional (Perroux, 1954: 335). ${ }^{2}$ Como veremos, la experiencia de la tolerancia no es exactamenteel caso estadounidense. En cambio, el tipo y la eficacia de la organización económica estadounidenses pronto valorizaron la inmensidad del espacio (agrícola, ganadero, industrial...) y sacaron partido de las libertades de la "inmensidad" en la "gran nación". Por contraste con Estados Unidos, vale la pena observar queen A mérica Latina y el Caribeel "complejo dela dimensión de la nación" Ilegó a ser frecuente: por sus dimensiones, Brasil "debía" ser una potencia, de la misma manera en queUruguay se hacía llamar la "Suiza de América", o que cualquier país pequeño explicaba su "atraso" por esa misma pequeñez (aún siendo del tamaño de Suiza o Bélgica), por haber sufrido mutilaciones territoriales (Bolivia, por ejemplo), o por tener "exceso de población" (El Salvador).

Finalmente, Estados Unidos, que no entró en grandes litigios fronterizos durante el siglo xx (en el xIx se anexó prácticamente la mitad del territorio mexicano), desconoce hasta cierto punto lo que Perroux ha llamado el "complejo de las fronteras naturales y las fronteras históricas". Por este complejo, la frontera adquiere un carácter sagrado que expresa la integridad del ser y la tradición nacional. Pero para Perroux, "los valores de la patria, para el moderno, no pueden confundirsecon un gregarismo primitivo", y es preciso recordar quecada nación histórica ha recibido aportes delas demás, como ha hecho aportes para las otras. Existen valores que relativizan la sacral ización dela nación y queson el patrimonio común de todos los hombres, como la libertad, la justicia y el amor (Perroux, 1954: 337). Las fronteras históricas de Estados Unidos, hasta llegar a coincidir con sus "fronteras

${ }^{2}$ Dicho de otro modo, entre frontera abstracta y frontera física. 
naturales", no estuvieron en tela de juicio durante todo el siglo xx. Estados Unidos no hizo grandes reclamos históricos sobre otras naciones (del tipo de Argentina sobre las Malvinas, o de Francia y Alemania sobre Alsacia-Lorena), ni fue objeto de dichos reclamos. En cambio, y a falta de convivencia con un número significativo de naciones, en Estados Unidos la sacralización de la nación adoptó fácilmenteun carácter religioso, queseacompañó dela sacralización dela libertad y dela propiedad privada (de lo que los estadounidenses entienden fundamentalmente por democracia y libre mercado). Las raíces de esta sacralización se encuentran desde antes dela formulación del Destino Manifiesto y se remontan hasta los primeros colonos, al grado de que Samuel P. Huntington ha querido reclamar que Estados Unidos es una nación de colonos antes que de inmigrantes (Huntington, 2004: 62-70). La "representación fronteriza" rebasa así la frontera nacional: la "frontera natural" se encuentra allí donde están la libertad y la propiedad privada inviolables, al modo en que se entienden en Estados Unidos, y al margen decual quier consideración o representación dela al teridad. Con su liberal ismo práctico, los Estados Unidos asumen que "Ias naciones están en otra parte que en sus fronteras nacionales" (Perroux, 1954: 367). Sólo que en el caso estadounidense, esta "conciencia" puedellegar hasta el integrismo religioso en la defensa de la democracia y el libre mercado, y convertirse en una peculiar "pulsión bélica", que amenaza al Otro cuando no se reconoceen esteespejo. AnneFournier y Catherine Picard han recordado hasta qué punto Estados Unidos es una nación religiosa, un país confesional. Si bien la Declaración de Independencia de 1776 consagra la libertad, lo hace de un modo muy distinto a la Declaración francesa de los derechos del hombre y el ciudadano de 1789. El texto francés dice que "los hombres nacen libres e iguales en derechos", mientras que el estadounidense reza que "los hombres han sido creados iguales y dotados por el Creador de ciertos derechos inalienables". La esencia religiosa del segundo texto se contrapone abiertamente con la esencia laica del primero (Fournier y Picard, 2004: 122). No es casual que Estados Unidos se haya convertido en el país de las sectas, pero, además, en la sede del $90 \%$ de las sectas consideradas peligrosas en el mundo (Fournier y Picard, 2004: 121). Al "exportar" estas sectas, 
Estados Unidos exporta solidaridades religiosas y "representaciones fronterizas" que rebasan las fronteras físicas nacionales, aunque siempre para beneficio de una red cuya sedeseencuentra en la potencia del Norte. A diferencia de Alemania hace ya varias décadas, Estados Unidos no parece tener la concepción de una "alma colectiva" (V olkgeist). En cambio, la defensa de los valores "americanos" puede llegar hasta el fanatismo religioso: la divisa es God bless A merica, como la del dólar es In God we trust. Elise Marienstras ha insistido en este aspecto fundador de la nación estadounidense, que se considera muy rápidamente "la realización de la voluntad divina" (Marienstras, 1976: 89), y dondela población ha sido "la elegida" para el "comienzo absoluto", más allá del tiempo histórico, ya que el pasado -por lo general europeo- es sinónimo de decadencia y corrupción (Marienstras, 1976: 62). “La creación nacional americana -escribe Marienstras- se funda sobre el principio de la discontinuidad histórica. En cierta medida, es antihistórica, y encuentra su tiempo en el milenio y sus ancestros en los héroes bíblicos..." (Marienstras, 1976: 41). El territorio se asocia con tanta fuerza con la propiedad privada por el peso que adquieren desde el principio los "granjeros-ciudadanos": "el territorio -escribe Marienstras- que es en Europa el verdadero cemento histórico de las naciones, es aquí [en Estados Unidos] un objeto que las generaciones se transmiten. Son [...] generaciones de desbrozadores que aseguran la continuidad de la nación por la suma detrabajos transmitidos de padrea hijo, no el territorio, queno es más que la materia prima en la empresa de cada ciudadano-granjero" (Marienstras, 1976: 326). Finalmente, por haber comenzado "desde cero" y sólo tener cara para el futuro, Estados Unidos no es una nación que reconozca los aportes de las demás (los inmigrantes rompen con su pasado), ni que pretenda aportar otra cosa que la seguridad de su "superioridad". Estados Unidos difícilmente relativiza sus valores en el contraste con los de otras naciones.

Ciertamente, como ya hemos afirmado con anterioridad, muchas demarcaciones fronterizas oficiales fueron difíciles de establecer en distintas latitudes, en la medida en que no coincidían con los límites de los grupos étnicos, tribales, clánicos u otros. En algunos casos, siguiendo el principio wilsoniano posterior a la Primera Guerra Mun- 
dial, algunos buscaron que las fronteras del grupo nacional y las del Estado coincidieran: fue lo que ocurrió en la antigua Yugoslavia en los años noventa del siglo pasado, como ya había sucedido en los Balcanes durante la primera mitad del siglo xx. Sin embargo, desde el último conflicto yugoslavo puede entreverse una nueva problemática: la de la búsqueda de la "limpieza étnica", aún a contrapelo de la experiencia histórica ("haciendo tabla rasa del pasado") y el establecimiento de barreras fronterizas claramente diferenciadas, impermeables al mestizaje. En cierto modo, es el modelo palestino-israelí, o el modelo del antiguo apartheid sudafricano. Pero también es una proyección de la política exterior estadounidense, como veremos enseguida.

En Estados Unidos, el multiculturalismo se ha puesto en boga desde hace al gún tiempo, no sin éxito. Los adelantos de este multiculturalismo lo han extendido hacia otras latitudes, aunque en éstas el panorama no sea forzosamenteidéntico al estadounidense. Existen razones profundas para el éxito mencionado: el multiculturalismo responde a la discriminación, y Estados Unidos es por excelencia el país dela segregación entre distintas comunidades nacionales, que una vez instal adas en el territorio estadounidense se convierten en comunidades étnicas, raciales o religiosas. Estos procesos de segregación en guetos crean fronteras internas que suelen ser fácilmente perceptibles, sobre todo en las grandes urbes, aunque comenzaran con el encierro de los indios (los "americanos nativos") en reservaciones. En el país del norte, los negros ("afroamericanos") también suelen ubicarse en estados, ciudades y barrios claramente delimitados, sobre todo si la raza coincide con la pobreza, como suele suceder. Algo similar pasa con los chicanos ("hispanos"), que en una ciudad como Los Ángeles, por mencionar un solo ejemplo, tienen su propia ubicación en barrios específicos. Algo parecido puede afirmarse de los puertorriqueños en Nueva York, o de los cubanos en Miami. Con los asiáticos (los chinos fueron objeto de persecución durante el siglo xIX) sucede algo idéntico: se agrupan en los famosos "barrios chinos" (chinatowns), de la misma manera en que los coreanos viven en los suyos. Como lo revelaran sucesos como los de Los Ángeles en 1992,3 la segregación no sólo

\footnotetext{
${ }^{3}$ Los motines luego de la gol piza contra el ciudadano afroamericano Rodney King.
} 
separa a las "minorías" de color de los blancos, sino que también enemista a las minorías entre sí, sobre todo si se especializan en profesiones diferentes, como es el caso.

Sería un error creer que la demarcación que establece las fronteras entre estos grupos es únicamente racial, y que separa de este modo a la población WASP (white, anglo-saxon and protestant) 4 de los demás, aunque se trate de una separación fundamental. También entre los grupos blancos seestablecen barreras que marcan la "frontera", como ocurre desde muy temprano con la instalación de comunidades alemanas en Pennsylvania (Marienstras, 1976: 278) que, primero aisladas, tardarán en "americanizarse". Desde el siglo xIx, por ejemplo, irlandeses e italianos (ambos grupos católicos) mantenían fuertes diferencias entre sí en una ciudad como Nueva York, donde vivían en barrios distintos, de la misma manera en que alemanes, suecos o judíos crearon sus propias comunidades aparte. La demarcación territorial es temprana y corriente. En Los Ángeles, por mencionar un ejemplo más, las disputas pueden llegar a la "pequeña guerra" por una u otra calle, como ocurre entre las pandillas demexicanos, salvadoreños y negros (afroamericanos).

Entre los "hispanos", como entre los asiáticos o entre los blancos, a la segregación en el espacio se agregan otras fronteras, que suelen pasar, como acaba de afirmarse, por la diferenciación en las profesiones: en Miami, por ejemplo, cubanos y haitianos no hacen los mismos oficios, de la misma manera en que entre los taxistas neoyorquinos sueleser frecuentela presencia deasiáticos (pakistaníes, afganos, etc.). Desdeeste punto devista, las representaciones fronterizas estadounidenses probablemente sean únicas en el mundo. Implican la proliferación de fronteras y representaciones fronterizas internas en una forma muy singular de territorialización (cercana en algunos aspectos al apartheid sudafricano). Si estas representaciones son únicas es porque la formación de la nación estadounidense no encuentra equivalentes en otras latitudes: aniquilados los indios, Estados Unidos se convierte en un país que recibe inmigrantes de las más diversas latitudes, pero que establece al mismo tiempo dos formas únicas de

${ }^{4}$ Blanca, anglosajona y protestante. 
integración, la democracia basada en la libertad individual, y el libre mercado, cemento del éxito material. La creencia en el éxito material (ubi panis, ibi patria) se instala muy pronto en un país que, en un principio, se alza contra las fronteras de clases en Europa y propone en cambio una relativa homogeneidad económica, con el "americano medio" que celebra St-John Crévecoeur como modelo (Marienstras, 1976: 291). Estados Unidos quiere aparecer como un país sin clases sociales, y exporta esta representación fronteriza por doquier: el futuro del libre mercado debe consistir en esta "nivelación" mundial. Finalmente, la nación estadounidense, de espaldas al pasado y de cara al porvenir, cuenta para consolidarse con ser una gran potencia, si no es que con ser "la" potencia internacional del futuro, Ilamada a exportar su "modelo" de "grandeza" material y espiritual al planeta entero (Marienstras, 1976: 304-336).

Por otra parte, el multicultural ismo, que encuentra su razón de ser en esta proliferación de minorías distanciadas entre sí, también anida en las desigual dades de otra índole, como las de género, al go sorprendente si se toma en cuenta, como lo hace notar Yves Lacoste, que las mujeres pueden ser mayoría en muchos de los países donde se identifican como "minoría" para hacer prosperar sus reivindicaciones identitarias. Lacoste subraya el carácter paradójico de la reivindicación identitaria:

el hecho de escoger la palabra "identidad" es sorprendente, porque su significado de alguna manera se ha invertido por el uso queseleha dado. Viniendo del latín idem, quesignifica "igual a", ha sufrido una evolución sorprendente: tradujo primero el parecido entre objetos o personas semejantes; designó luego lo que no cambiaba con el transcurso del tiempo en las características de un individuo (de ahí el carnet de identidad); hoy, la noción de "identidad" y el adjetivo "identitario" sirven por el contrario para marcar diferencias en el seno de una sociedad, y, para al gunos grupos, para reivindicar el "derecho a la diferencia" (Lacoste, 1997: 173-174).

El autor de referencia no deja de recordar los peligros de una política "identitaria" en algunos países europeos, donde el multicul- 
turalismo puede ser un signo de americanización. Así, en el Reino Unido, el principio de subsidiariedad ${ }^{5}$ provocó que las autoridades terminaran por admitir el carácter mayoritario de los inmigrantes en barrios deal gunas ciudades y su derecho a escoger sus propias autoridades (religiosas, por ejemplo). Como lo recuerda Lacoste, es deenclaves pakistaníes en estas ciudades que partieron los movimientos islamistas extremistas que exigían la muerte de Salman Rushdie (Lacoste, 1997: 220). Al igual que en Estados Unidos, algunos grupos políticos han buscado practicar en Europa una "estrategia de gueto" para controlar a una minoría cultural y obligarla a vivir aparte del conjunto dela población. Setrata, defacto, deuna política deapartheid (Lacoste, 1997: 185) que puede llegar aún más lejos en el caso de las reivindicaciones regionalistas (corsos, vascos, catalanes, flamencos, valones...) y que por un momento pareció contagiar a Europa, sobre todo en los años noventa del siglo pasado. Los extremos se tocan: el ultranacionalismo, por una parte, y el "cosmopolitismo" a ultranza de las "comunidades" que forman redes multiculturales transnacionales, por otra. Si el multiculturalismo llega a sus extremos, no es imposibleque lleguea poner en duda la idea misma de nación, y que provoque reacciones como las de Samuel P. Huntington en Estados Unidos, quien, de manera harto paradójica, termina por reivindicar a la vez la asimilación y la supremacía angloprotestante (Huntington, 2004: 213-258).

Así pues, en la proyección de las "representaciones fronterizas" estadounidenses hacia el exterior pueden coincidir dos formas igualmente injerencistas: la sacral ización de una "frontera histórica" siempre móvil (la frontera de la democracia y el libre mercado) y la proliferación de las compartimentaciones multiculturales. Ello supone que el "resto del mundo" asuma la fe en la democracia (el ritual el ectoral) y el libre mercado, y acepte al mismo tiempo la rel evancia del multiculturalismo, aunque en Estados Unidos los partidarios de lo primero y lo segundo con frecuencia sean distintos. Una política de estetipo no deja de representar problemas para otras latitudes, como

5 “Compensación” para los inmigrantes. 
ha ocurrido en Europa. Con la integración en la UE, en efecto, se ha corrid o el riesgo de que las regiones, primero, y los inmigrantes, más tarde, reclamen "compensaciones": el problema regional plantea en al gunos casos readecuaciones fronterizas, mientras queel migratorio supone crear demarcaciones territoriales específicas (como las musulmanas en las ciudades inglesas). Se trata de políticas quelas autoridades de la ue han rechazado con cierta frecuencia: sería un modo de americanizar a Europa.

Asimismo, algunos autores consideran que se trata de políticas auténticamente "posmodernas", en el sentido de que disuelven varios de los atributos de la modernidad: entre ellos, la demarcación de la frontera entre la esfera pública y la esfera privada. La reivindicación del "particularismo cultural", como decual quier otra identidad, puedeser admisible en el ámbito privado, pero no tiene por qué desbordar este marco para invadir el espacio público democrático, lugar dedesplieguedela razón, dela formal ización y la aplicación del derecho, mientras que el espacio privado es el lugar de la vida íntima, de las convicciones y las pasiones (Wieviorka, 1997: 21-22). Como lo afirma Dominique Schnapper (citado por Michel Wieviorka, 1997: 39):

si las especificidades culturales de los grupos particulares son compatibles con las exigencias de la vida común, los ciudadanos y los extranjeros regularmente instalados en el suelo nacional tienen el derecho de cultivar sus particularidades en su vida personal como en la vida social, a condición de respetar las reglas del orden público. Este derecho está inscrito en los principios mismos del Estado de derecho y dela democracia moderna. Las libertades públicas aseguran la libertad de asociación, el derecho de practicar libremente la religión o de utilizar la propia lengua. Pero al mismo tiempo, estas especificidades no deben fundar una identidad política particular, reconocida como tal en el interior del espacio público.

Es esta entrada de la esfera privada en la pública la quepuede convertir al multicultural ismo en un factor político injerencista, si rebasa las fronteras oficiales entre naciones. 
Si en Estados Unidos se produce este desbordamiento, es con frecuencia porque, como sucede en el ethnic business, ${ }^{6}$ la reivindicación multicultural traspasa las fronteras para convertirse en un factor de lobbying (grupo depresión) en el espacio público. En Europa, en cambio, Ilega a asociarse esta proliferación de particularismos con el drama de una sociedad como la libanesa, que vivió años de guerra civil con el debilitamiento del espacio público estatal y la explosión delos confesionalismos (Wieviorka, 1997: 39). Más que el vigor democrático, en otras sociedades el ascenso del multiculturalismo y la "naturalización" de querellas como las étnicas traduce el debilitamiento del espacio público y de la tradición republicana, aunque haya que criticarle su universalismo demasiado abstracto. Bien puede ocurrir que los medios de comunicación masiva, fácilmente influenciables por la americanización, contribuyan a propagar todos los particularismos hasta donde pueden convertirse en novedades, al menos por un tiempo (dichos medios trabajan sistemáticamentecon la "novedad", recogiéndola o creándola). Hasta aquí, podemos afirmar entonces que, en sí, el multiculturalismo tiene aspectos positivos (no se trata de negar el pluralismo cultural, ni de dejar a las minorías sin protección alguna) y negativos: cabe insistir sobre todo en que es el producto de una sociedad singular, con fuertes fronteras internas creadas por una competencia acérrima, y que produce otros efectos cuando se exporta al exterior. La representación de la frontera en Estados Unidos adquiere "pulsiones bélicas" desde el momento en que pretende hacer pasar sus singularidades por "modelo" universal: la fe y la etnia, transnacionales, no reconocen soberanías nacionales. Desde nuestro punto de vista, no existe razón alguna para que otras sociedades, con problemáticas distintas, recojan tal cual la problemática multicultural y sus consecuencias. ¿Se trata acaso de "representaciones fronterizas" que guardan relación con la historia latinoamericana y caribeña?¿Cuál es la "representación fronteriza" predominante en el subcontinente americano?

6 "Negocio étnico". 


\section{Singularidades en América Latina y el Caribe}

En muchos aspectos, la conformación territorial de América Latina y el Caribe ha sido diferente dela estadounidensey bastantemás diversa que ésta. Hasta hoy, no es raro que los espacios del subcontinente suelan desconocerse unos a otros dentro de un mismo Estado nacional. Sobre el regional ismo colombiano, por ejemplo, ha escrito M ario A. Murillo (2004: 46):

El profundo regionalismo es difícil de comprender, aunque cuando se viaja por el país golpea inmediatamente. Los pescadores que viven en la costa del Caribe no tienen absolutamente ninguna conexión con los campesinos indígenas de la región amazónica, mientras los bogotanos de clase media encuentran poca relación con los campesinos afrocolombianos de la región bananera de la costa del Pać́fico. Estos son unos pocos de los muchos regionalismos que existen, ignorados a diario por los muros del poder. Como un miembro independiente del Congreso me dijo recientemente: "Ia gente en la ciudad se preocupa cada vez menos por lo quele sucedea los campesinos; es como si vivieran en dos países diferentes".

Frecuente en distintos países dela región, esta problemática muestra que aún no existen los "transportes mentales" necesarios para que la comunicación entre los distintos espacios nacionales-incluidos los fronterizos- quede integrada. De este modo, como ya lo habíamos sugerido, las "representaciones fronterizas" se estancan en lo local, no alcanzan proyección exterior y no imaginan la alteridad. Puede ocurrir incluso queesta representación local se "transnacional ice" (por contacto con transnacionales o por migraciones, como ya lo habíamos sugerido), pero quelo haga de espal das al Estado nacional en su conjunto. Aunque también existen en Estados Unidos, ${ }^{7}$ es probable que los regionalismos sean mucho más fuertes en América Latina y el

${ }^{7}$ Costas Este (Nueva York) y Oeste (California) "cosmopolitas" y demócratas;

"A mérica profunda" del centro y el sur, republicana. 
Caribe. Luego de las independencias, esos regional ismos resquebrajaron uniones como la grancol ombiana o la centroamericana, en un proceso que no siguió por cierto líneas étnicas, sino particularismos locales y caprichos caudillistas. En vez de unificarsey ampliarse, como en Estados Unidos, la unidad de las antiguas coloniales españolas se resquebrajó. Algunos han visto en ello una diferencia fundamental entre Estados Unidos y el sur del continente: los estadounidenses se orientan por el sentido del espacio -ampliado- más que por el del tiempo, mientras que América Latina y el Caribe están dominados por un complejo entrelazamiento entre ambos (Hennessy, 1978: 3).

El mercado interno del subcontinente no está plenamente integrado, y, en estas condiciones, no aparece prácticamente ninguna de las "sicosis de localización" a las que se refiriera Perroux: con todo, a veces tiendea creerseen una "sobrepoblación" queen realidad no es tal (ni siquiera en un caso como el salvadoreño), en la excesiva pequeñez de algunos países (el mismo El Salvador, "pulgarcito de A mérica"), o quedan casos en los cuales las fronteras naturales no coinciden con las fronteras históricas reclamadas (Bolivia reclama salida al mar, el Ecuador un territorio amazónico mayor...). No hay grandes potencias en el subcontinente, ni siquiera en el caso de Brasil, ni "pulsiones bélicas" que desborden las unidades territoriales autónomas. En cambio, las fronteras suelen ser mucho más diversificadas -y con más Estados (con frecuencia entre tres y cinco)que las fronteras relativamente simples de Estados Unidos. En estas condiciones de diversificación, no deja de sorprender que el subcontinente americano se haya caracterizado por su estabilidad geopolítica, en comparación con otras latitudes. En algunos casos, algunos gobiernos han tratado de utilizar las rivalidades fronterizas para lograr legitimidad interna (dictaduras o gobiernos civiles), pero son los menos. Otro indicio del poco interés por los litigios es la Ilamativa escasez de estudios geopolíticos en el subcontinente.

La estabilidad de las fronteras no obedece de modo directo a su desvalorización: es previa a la globalización, como es previa al multiculturalismo, y parece haber convertido a la "gran región" en nación, aunqueen ésta subsistan los particularismos dela "subregión". Desdeel punto devista del multiculturalismo, quizá convenga indi- 
car que únicamente dos fronteras separan a una población del mismo origen en toda A mérica Latina y el Caribe: la frontera entre México y Guatemala (población maya), densamente poblada, y la frontera entre Perú y Bolivia (población aymara), ambas particularmente estables durante el siglo xx, aunque la incorporación de Chiapas al territorio mexicano haya planteado problemas en el siglo xIx. En este mismo marco, difícilmente podría olvidarse que la población precolombina, más allá de los imperios azteca e inca (que no tenían equivalentes en el norte americano), se encontraba muy diversificada a la llegada de los españoles. No fue aniquilada sistemáticamente, al modo de la población nativa estadounidense, pese al dedive del siglo posterior a la Conquista (efecto sicológico de la Conquista, trabajos forzados en las minas, enfermedades desconocidas...). Deeste modo, no existe en el subcontinente americano ninguna frontera que siga líneas étnicas: las fronteras suelen seguir líneas geográficas (ríos o cadenas montañosas), líneas imperiales (que hasta hoy separan al mundo portugués del español), líneas de más reciente demarcación, aunque muy pocas producto de guerras, y algunas líneas que coinciden con trazados de concesiones para empresas transnacionales petroleras (Ecuador-Perú, Chaco) o bananeras (Guatemala-Honduras) (Foucher, 1986: 171). Otras tienen relación con arbitrajes estadounidenses (Haití-República Dominicana). Las fronteras posteriores a la independencia que siguen trazados distintos de los coloniales representan las tres cuartas partes del total (Foucher, 1986: 182). En este marco, una excepción notoria se encuentra en México, que perdiera la mitad de su territorio en el siglo XIX, y cuya frontera con Estados Unidos sigue la línea del Río Bravo (el "río Grande"). Cuando se fijó esta frontera, el Estado mexicano, vulnerable, se debatía entre los "cuartelazos" (entre ellos los de Santa Anna), el escaso control del norte aún poblado por comanches, apaches, yaquis y mayos rebel des, y la "guerra de castas" en el otro extremo, en Yucatán.

Dentro de los países latinoamericanos y caribeños, las demarcaciones étnicas, aunque existen, son mucho menos importantes que en Estados Unidos: habida cuenta del mestizaje en el subcontinente, las demarcaciones tienen rasgos mucho más abiertamente sociales (un apartheid social y no étnico), aunque las probabilidades de vivir en la pobreza son mayoressi sees deorigen indígena o negro (afroamericano), 
aunque existen excepciones (otaval eños en Ecuador, por ejemplo). Ciertamente, también en las ciudades latinoamericanas y caribeñas existen-por citar un caso- los chinatowns (como existen comunidades alemanas relativamente segregadas en Venezuela y Chile), pero el ordenamiento territorial del conjunto no sigue pautas étnicas o raciales rígidas. Tampoco hay demarcaciones demasiado rígidas y territoriales entre la población de origen extranjero: si acaso quepa notar, por ejemplo, cómo los españoles suelen mantener sus propios regionalismos (vascos, catalanes, asturianos...) en asociaciones, clubes, restaurantes...

El hecho de que los conflictos fronterizos sean desde hace al gún tiempo mínimos en el subcontinentey quehayan abarcado menos del $3 \%$ delas líneas fronterizas (Foucher, 1986: 159) permite suponer que la conciencia nacional ha avanzado de manera más o menos rápida, a diferencia de lo ocurrido en otras latitudes (África y Asia). En realidad, la ausencia de este tipo de conflictos es una herencia particular: desde tiempos coloniales, los espacios fronterizos estuvieron mal integrados y eran poco conocidos, al grado de que en ocasiones podían ser vistos como espacios de "Ieyenda", al go sobre lo que habremos de volver. Durantela Colonia, el poblamiento no avanzó hacia los espaciosfronterizos, como lo muestran las bajas densidades poblacionales: eran inferiores en las fronteras a un habitante/ $\mathrm{km}^{2}$ (Foucher, 1986: 174). Hacia 1810-1820, según H umboldt, había en la región 20 millones de habitantes en más de 22 millones dekm², y la población ascendía a 62 millones de habitantes en 1900 (Foucher, 1986: 169). Los centros coloniales, que concentraron la población, solían encontrarse lejos de las fronteras. Desdeel siglo xIx, fueron objeto dealgunos litigios, a veces en extremo sangrientos, y deintervenciones extranjeras, quellegaron a utilizar los particularismos regionales para influir en la creación de al gunos Estados nacionales, como los llamados “Estados-tapón” (Uruguay, pero también, en cierta medida, Paraguay y Bolivia).

Fuera de las antiguas leyendas de El Dorado, no hay mitos nacional istas sobre las fronteras latinoamericanas y caribeñas (salvo, hasta cierto punto, con los bandeirantes brasileños). Las tesis deun F.Jackson Turner para Estados Unidos no funcionan en el Sur (Hennessy, 1978: 6-27). Como lo ha hecho notar A listair Hennessy, en A mérica Latina y 
el Caribe se trata más de "las fronteras" y los "límites territoriales" que de "Ia" frontera (frontier), que en Estados Unidos designa por lo demás el movimiento hacia la Conquista del Oeste, más que los límites territoriales con México o Canadá (borders). Si bien es cierto quelas fronteras latinoamericanas y caribeñas muestran una diversidad mayor que las estadounidenses, la riqueza, desdeel oro hasta el caucho, pasando por la ganadería y el petróleo, es explotada desdeel siglo XIx, con harta frecuencia, por empresas extranjeras: la expansión o la contracción de la frontera responde a demandas de mercado externas (Hennessy, 1978: 21). ¿Cómo podía forjarse en estas condiciones un mito nacionalista de la frontera y un conjunto de "representaciones fronterizas" sólidas? La valorización delas regiones fronterizas sehizo en muchos países de espal das al Estado nacional, que a veces ni siquiera estaba enterado de lo queocurría en esos espacios (del trato de las transnacionales hacia los indios, por ejemplo), aunque se tratara más de fronteras de inclusión (desde el punto de vista étnico) que de fronteras de exclusión al estilo estadounidense, con su carga de "naturaleza germánica" y deromanticismo agrario contra el estilo devida de las ciudades (Hennessy, 1978: 19-20). Las fronteras latinoamericanas y caribeñas funcionaron en muchas ocasiones como enclaves en manos extranjeras, y de las que los Estados nacionales obtenían apenas unascuantas "regalías". Tratándoseademás degrandestransnacionales, se está lejos del pequeño granjero-ciudadano que construye la nación estadounidensey hace avanzar la frontera hacia el Oeste. Tampoco es raro que, al cabo de cierto tiempo, saqueado el territorio fronterizo latinoamericano, las empresas transnacionales hayan abandonado el lugar, para que volviera al olvido y al desconocimiento.

En el siglo xx, dos elementos más se han agregado a estas singularidades fronterizas en América Latina y el Caribe. En algunos países, incluso de modo tan tardío como en los años setenta, gobiernos con frecuencia militares, concientes de las riquezas en la frontera, promovieron la "colonización" de la misma por población proveniente del interior (Oriente ecuatoriano, por ejemplo). En otros casos, las regiones fronterizas fueron lugares en los cuales se instalaron grupos guerrilleros (Colombia, Guatemala, Perú), que aprovecharon justamente la escasa presencia del Estado nacional. En al gunos casos, los grupos 
guerrilleros llegaron a causar, por su movilidad y sus incursiones, tensiones fronterizas (Colombia y Venezuela), aún en zonas ricas en petróleo. La persecución contra estos grupos reforzó la presencia del Estado nacional -fuerzas armadas- en las regiones defrontera. Finalmente, éstas, por su porosidad y sus antecedentes de actividades de contrabando (frontera entre Colombia y Venezuela, por ejemplo), se convirtieron en territorios idóneos para la producción o el tráfico de droga (Perú, Colombia). Así, desde la frontera violenta se enriquecieron algunos países, aunque las regiones productoras o traficantes de estupefacientes fueran desconocidas para buena parte de la población local, como el Huallaga para los peruanos serranos y costeños. En A mérica Latina y el Caribe, la frontera no deja de asociarse con un mundo violento y azaroso, aunque, por encontrarse "al margen", no sea forjador de mitos nacionalistas. La frontera en el subcontinente ocupa un lugar marginal, en la periferia delas periferias; en la historia de Estados Unidos, en cambio, la frontera y la Conquista del Oeste pronto ocuparon un lugar central, sobre todo durante el siglo xIx. Si acaso, sólo con Sarmiento en Argentina se llega a "teorizar" sobre la diferencia entre la "civilización" de las ciudades y la "barbarie" del interior, que aún no ha sido incorporada del todo al espacio nacional, y que en este caso sí incluye el exterminio de los indios. Con todo, esa visión es distinta de la estadounidense, que, antes de exterminarlo, alcanza curiosamente a ver en el "buen salvaje" la "virginidad" del Nuevo Mundo, por contraste con la corrupción europea. Si en Sarmiento la América Latina civilizada es la "europea", en Estados Unidos, donde en realidad no hay claridad sobre la problemática, se intenta crear un civilización propia por oposición a la decadente Europa (a la que se opone el "buen salvaje") y por oposición al salvajismo indio (al queseoponela "civilización" traída por los inmigrantes). Universalismo y diferencialismo van dela mano de un modo muy particular, como lo ha explicado Elise Marienstras.

\section{Conclusiones}

En la actual idad, como señalamos al principio deesteestudio, los conflictos armados fronterizos en el mundo se han opacado casi hasta 
desaparecer. Como en Europa o en otras latitudes (África y A sia), en A mérica Latina y el Caribe las fronteras son, hoy por hoy, muy estables. Lo fueron durante el siglo xx, por contraste con África y Asia. Esta condición refleja, al mismo tiempo, una conciencia nacional más avanzada y, paradójicamente, un relativo desconocimiento del valor de los espacios fronterizos, que son marginales. Desafortunadamente, ese val or, con frecuencia, fue descubierto por extranjeros quesacaron provecho de espaldas al Estado nacional. En todo caso, y pese a los nacionalismos, América Latina y el Caribe tampoco conocieron durante el siglo xx las grandes "sicosis de localización" que, en más de una ocasión, empujaron hacia la guerra. Como lo han señalado al gunos autores (Foucher, Hennessy), las fronteras latinoamericanas y caribeñas, desde el punto de vista geopolítico, se han caracterizado desde hace mucho tiempo por ser espacios interestatales pacíficos, aunque ello no quiera decir que las regiones fronterizas internas no sean violentas. La incorporación muy tardía de los espacios fronterizos ha permitido que la violencia (guerrillas, narcotráfico) subsista hasta el siglo xxı. Como sea, la relación con la frontera en el subcontinente americano pareciera haberse ajustado bastante al ideal westfaliano y europeo.

El caso estadounidensees, curiosamente, diametralmentedistinto. Si Estados Unidos no deja de ser un imperio, lo es en la medida en que la "verdad revelada del emperador" no reconoce fronteras: en este caso, el "emperador" (el presidente) es una figura emblemática de una nación que, desde sus primeros días, se ha creído "elegida por Dios" y llamada a ejecutar una "misión divina". A ntecierta debilidad de los cimientos internos de la nación, por las diferencias étnicas y raciales, Estados Unidos ha tendido a construir su "grandeza" en las demostraciones defuerza hacia los demás: ciertamente, suelen ser demostraciones orientadas por igual hacia el exterior que hacia el interior dela potencia. El hecho es quelas "representaciones fronterizas" estadounidenses no se detienen en lo local: a partir dela formulación del Destino Manifiesto, a finales del siglo xIx, se proyectan hacia el exterior "como si" la Conquista del Oeste debiera proseguir en otras latitudes. La fe-que suele llegar a fanatismo religioso- no reconoce soberanías nacionales, ni se considera impedida para "entrar" en el 
espacio del otro: Estados Unidos lo hace demil maneras, entrelas que se incluyen las redes de todo tipo, incluidas las multicultural es. Paradójicamente, con esa feen el ritual electoral y en el mercado, Estados Unidos suele exportar también sus compartimentaciones étnicas, raciales y religiosas, que probablemente se encuentran entre las más acentuadas del mundo. En estas condiciones, ni el liberalismo ni el multicultural ismo a ultranza debieran aceptarse de manera acrítica. Pero lo cierto es que Estados Unidos, sin dejar de reforzar la frontera física con México, exporta "representaciones fronterizas", culturales en particular, que se presentan como "modelo" para espacios donde todavía prevalece lo local y comunitario. Es una política injerencista, tanto más eficaz cuanto que es invisible, y llama a darle la espal da al Estado nacional: por la fe ciega en que no hay más model o que el que “Dios eligió" para Estados Unidos, y por las divisiones a ultranza que el multiculturalismo puede suscitar.

\section{Bibliografía}

Badie, Bertrand, 1995, La fin des territoires. Essai sur le désordre international et sur l'utilité sociale du respect, Fayard, París.

Burke, Peter, 2000, Formas de historia cultural, Alianza, Madrid.

Escobar Villegas, Juan Camilo, 2000, Lo imaginario. Entre las ciencias sociales y la historia, Fondo Editorial-Universidad Eafit-Cielos de Arena, Medellín.

Foucher, Michel, 1986, L'invention des frontiéres, Fondation pour les Etudes de la Défense Nationale, París.

Fournier, Anne y Catherine Picard, 2004, Sectas, democracia y mundialización. La falsa espiritualidad y la manipulación de los individuos, Paidós, Barcelona.

Hennessy, Alistair, 1978, The Frontier in Latin A merican History, Universty of $\mathrm{N}$ ew Mexico Press, Albuquerque.

Huntington, Samuel P., 2004, ¿Q uienes somos? Los desafíos de la identidad nacional estadounidense, Paidós, México.

Lacoste, Yves, 1997, V ivela nation. D estin d'uneidéegéopolitique, Fayard, París. 
Marienstras, Elise, 1976, Les mythes fondateurs de la nation américaine, Maspero, París.

Murillo, Mario A., 2004, Colombia y Estados U nidos. Guerra, inquietud y desestabilización, Popular, Madrid.

Perroux, Francois, 1954, L'Europe sans rivages, Presses Universitaires deFrance, París.

Wieviorka, Michel (ed.), 1997, U nesociétéfragmentée? Lemulticulturalisme en débat, La Découverte, París.

Artículo recibido el 28 de marzo de 2005 Artículo aprobado el 13 de mayo de 2005 